\title{
Dynamical Behaviour of Very High Strength Nitrogen Alloyed Steels
}

\author{
A. Lichtenberger, E. Lach and F. Rondot \\ Institut Franco-Allemand de Recherches Saint Louis, 5 rue du Général Cassagnou, B.P. 34, \\ 68301 Saint Louis cedex, France
}

\begin{abstract}
The dynamical behaviour of some nitrogen alloyed steel are investigated. These steels with two different levels of high hardness were obtained by cold drawing. Static and dynamic compression tests are carried out as well as quasi dynamic tests at intermediate rate. Flow curves are analysed in terms of strain rate sensitivity, maximal strain before rupture and mechanical instability. Cylinder impact tests on a rigid boundary are performed at various velocities. The profile of the specimens shows a markedly difference in the plastic deformed zone. $\dot{A}$ constitutive law has been chosen, based on the Johnson-Cook model. Results of calculation are discussed in comparison to experimental data in the plastic zone. Microscopic observations shows the formation of strain and damage localization in the different test conditions
\end{abstract}

\begin{abstract}
Résumé. Le comportement dynamique de certains aciers alliés à l'azote est étudié. Ces aciers possédant deux niveaux de dureté élevés différents ont été obtenus par étirage à froid. Des essais de compression statique et dynamique sont effectués ainsi que des essais quasi-dynamiques à vitesse intermédiaire. Les courbes de contrainte d'écoulement sont analysées en terme de sensibilité à la vitesse de déformation, de déformation maximale avant rupture et d'instabilités mécaniques. Des essais d'impact de cylindres sur cible rigide sont réalisés à différentes vitesses. Le profil des échantillons montre une différence très nette dans la zone déformée. Une loi de comportement a été choisic, basée sur le modèle de Johnson-Cook. Les résultats de calcul sont discutés en comparaison avec les données expérimentales dans la zone plastique. Les observations microscopiques montrent les localisations de la déformation et de l'endommagement pour les différentes conditions de chargement.
\end{abstract}

\section{INTRODUCTION}

High strength steels are of great interest in many applications but their use is limited by the dual competition between strength and toughness. On the other side, in dynamic compression, the formation of adiabatic shear bands and the high level of hardness brings some difficulty in the determination of the mechanical behaviour. Nitrogen alloyed steels have an austenitic structure (FCC). They can achieve very high level of strength by thermomechanical treatment; but in comparison to martensitic steels they show an unusual behaviour in the amount of strain before rupture and in their dynamical properties [1].

Simulations of dynamical phenomena requires to take into account the real behaviour of material in a wide range of application in the strain rate, temperature and strain, through adequate constitutive law. The determination of stress-strain curves for different conditions of temperature and strain rate in the uniaxial stress state is needed for the fitting of the different coefficients. There is a great interest to use a simple, even empirical model with reduced parameters as in the model of Johnson-Cook that is currently used in different dynamical codes.

Taylor tests are used for the verification of models. Usually a good agreement is found between experiment and calculations, because comparisons are made on the basis of the total length and one or two mean diameters [2]; such global value are not very sensitive to the models and an accurate examination of 


\section{MATERIALS}

An austenitic nitrogen alloyed steel (named P900N) was studied. The chemical composition is shown in table 1 .

Table 1: Chemical composition of P900N

\begin{tabular}{|c|ccccccccc|}
\hline P900N & $\mathrm{C}$ & $\mathrm{Si}$ & $\mathrm{Mn}$ & $\mathrm{Cr}$ & $\mathrm{Mo}$ & $\mathrm{Ni}$ & $\mathrm{P}$ & $\mathrm{S}$ & $\mathrm{N}$ \\
\hline$[\%]$ & 0.03 & 0.06 & 19.33 & 19.68 & 1.99 & 0.1 & 0.01 & 0.001 & 0.85 \\
\hline
\end{tabular}

Nitrogen alloyed steels possess a high amount of $\mathrm{Mn}$ and $\mathrm{Cr}$ because they increase the solubility of nitrogen and do not have a strong nitride forming tendency. The characteristics of this kind of steels depend on nitrogen in interstitial solution. In industrial scale P900N can only be produced in a pressureelectro-slag-remelting(PESR)-facility. This method needs a solid nitrogen carrier [3]. Silicon nitride fulfills the requirements but augments silicon contents up to $0.8 \%$. For that reason the studied alloy (table 1) was melted in a laboratory.

The typical features of the deformation structure of austenitic steel are: a) planar glide at low total strain, b) deformation twinning at intermediate and high strain, c) shear band formation at failure strain. Increasing nitrogen contents affects the evolution of the microstructure, $i$. e. the onset of twinning is shifted to lower strains and higher stresses [4].

Nitrogen alloyed steels are coldly deformable to very high strains because no strain-induced martensite occurs. This alloy was strain-hardened by cold drawing to a hardness of HV30 = 429 (I) and HV30 $=540$ (II). Even more than $80 \%$ deformation is necessary to reach $\mathrm{HV}=540$. Mechanical values drawn by tensile tests are listed in table 2 .

A typical behaviour of nitrogen alloyed steels is reduced uniform elongation. Table 2 shows the total elongation at $\mathrm{A}=10 \%$ compared to necking of $\mathrm{Z}=56 \%$ (steel I). The cold drawn bars being examined by compression tests, a Bauschinger effect is expected. So the initial state of the studied material is characterized by a high density of deformation twins and shearbands [5].

Table 2: Mechanical value drawn by tensile test

\begin{tabular}{|c|cc|}
\hline & Steel I & Steel II \\
\hline Rp [MPa] & 1825 & 2270 \\
\hline Rm [MPa] & 1859 & 2320 \\
\hline A [\%] & 10 & 7 \\
\hline Z [\%] & 56 & 43 \\
\hline HV30 & 429 & 540 \\
\hline
\end{tabular}

\section{EXPERIMENTAL RESULTS}

\subsection{Testing Procedure}

Cylindrical specimens were machined $5 \mathrm{~mm}$ diameter and 5 to $7 \mathrm{~mm}$ length. All the samples are lubricated with a special lubricant that minimizes the contribution of friction during testing. True stress-strain curves are determined in the uniaxial compression state at various strain rates by room temperature.

Quasi-static compression tests are conducted on a screw driven load frame at a strain rate of $10^{-3} / \mathrm{s}$. An hydraulic universal testing machine is used for the quasi-dynamic compression at strain rate of $1 / \mathrm{s}$. Interrupted tests are also performed to obtain a better description of material in the isothermal conditions

Dynamical compression tests are conducted at a strain rate of about 3000/s using a Split Hopkinson Pressure Bar. In order to obtain the deformation of the high strength steels without indentation of the bars special bars with very high hardness are also used; for this purpose sintered tool steel has been heat treated up to a Rockwell hardness of 67HRC. A good straightness has been achieved and tests have shown the ability of such materials to support high impact stresses without plastic deformation or rupture. Short rise time were used for the incident wave in order to get a rapid answer of the material behaviour.

Several cylinder impact tests were conducted. Tests feature cylinders having a $6 \mathrm{~mm}$ diameter with $40 \mathrm{~mm}$ length and various velocities ranging from 137 to $240 \mathrm{~m} / \mathrm{s}$, against a tungsten carbide target.

\subsection{Compression stress-strain behaviour}

Figure 1 shows the results obtained for the nitrogen alloyed steel type I. At intermediate strain rate interrupted tests are performed in order to get the behaviour under quasi-isothermal conditions. The response of the material at a strain rate of $1 / \mathrm{s}$, compared to that by static conditions shows little variation 


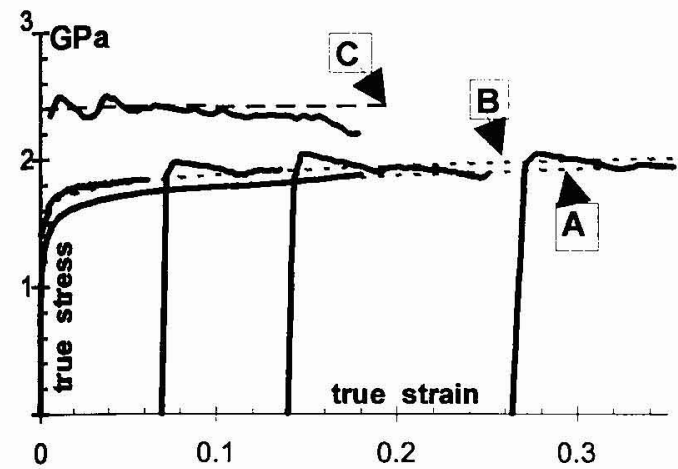

Figure 1: True stress strain compression flow curves for steel I at strain rate $0.001,1$, and $4100 \mathrm{~s}^{-1}$

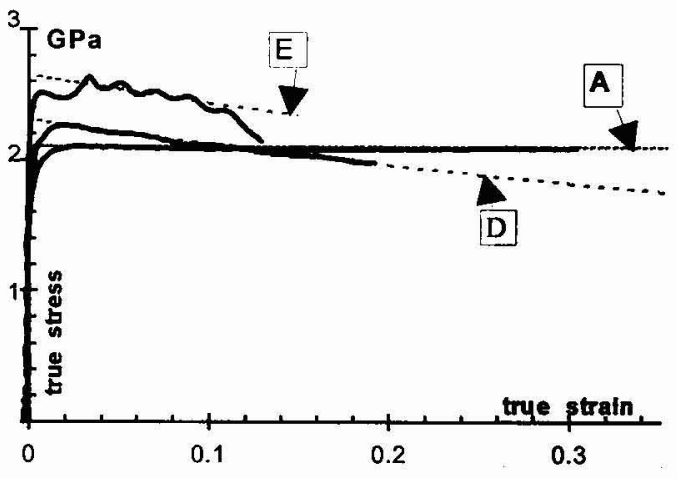

Figure 2: True stress strain compression flow curves for steel II at strain rate $0.001,1$, and $2300 \mathrm{~s}^{-1}$

in the value of strain hardening and only a slight increase in the flow stress. For higher strain rate the material shows a higher flow stress, reaching $2400 \mathrm{MPa}$ at 4100 /s. The strain rate sensitivity in the range above 1/s is very important especially for a material with FCC structure and compared to classical high strength martensitic steels with similar hardness. The other particularity of this steel is the high amount of plastic deformation, until $20 \%$, which is also unusual for a classical high strength steel.

Steel II has a higher hardness, and higher level of stresses were expected. Typical true stress strain curves at various strain rates are shown in figure 2 . The curve at intermediate rate is given in the adiabatic conditions. In the static condition the flow stress is about $30 \%$ higher than for steel I but with reduced strain hardening. At high strain rate $(2300 / \mathrm{s})$ the flow stress difference becomes less than $10 \%$; this corresponds to a smaller strain rate sensitivity for this steel which has undergone the highest cold drawing. Under adiabatic conditions the stress-strain curves show a pronounced decrease in the flow stress as plastic strain increases.

In order to verify if this decrease is only due to a thermal softening, temperature measurement are made with thermocouple. A linear increase of temperature with strain is obtained in the adiabatic conditions. For $18 \%$ total plastic strain $60^{\circ} \mathrm{C}$ has been measured. Figure 3 shows the difference of flow stress due to the thermal softening between adiabatic and quasi-isothermal conditions, using the method of interrupted tests. From these results, the thermal softening can be estimated at about $270 \mathrm{MPa} / 100^{\circ} \mathrm{C}$, which is a little more than the value obtained by Paulus [5] in the temperature tests. Even for the quasi-isothermal test, a strain softening can be observed with a regular decrease of stress with increasing plastic strain. This effect can be influenced by some damage resulting from the presence of localized shear bands due to dynamic loading.

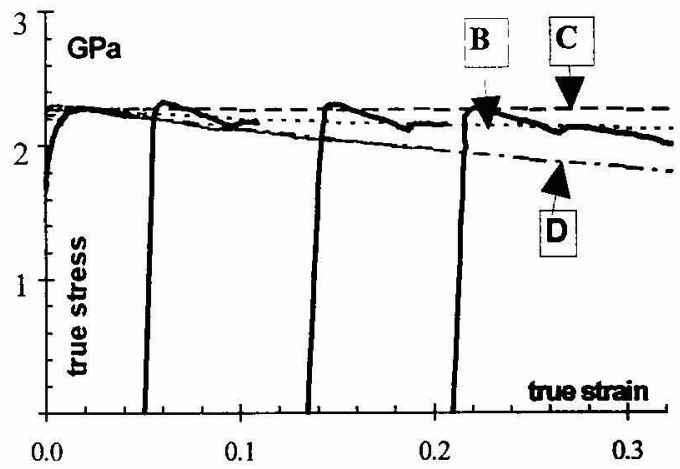

\subsection{Cylinder impact test}

Figure 3: Adiabatic and quasi-isothermal true stress strain compression flow curves for steel II at strain rate $1 \mathrm{~s}^{-1}$

The final profile was measured with a laser micrometer. Tests with any fracture are not valid. Steel I could be shot at higher velocities than steel II which is more brittle and allows only a limited plastic deformation.

Experimental results on the variation of the radius of the impacted projectiles are given figure 4 and 5. Profiles are obtained for different velocities; but the particularity of these results is the difference observed between the two type of steels for the same velocity, around $140 \mathrm{~m} / \mathrm{s}$. One of the main purpose of this work was to check the ability of numerical simulation to reproduce this singularity taking into account the behaviour of the material in compression. 


\section{NUMERICAL RESULTS}

\subsection{Constitutive law}

Johnson-Cook model is a quite simple model that represents an empirical relationship for the von Mises flow stress [6].

$$
\sigma=\left[\mathrm{A}+\mathrm{B} \cdot \varepsilon^{\mathrm{n}}\right]\left[1+\mathrm{C} \cdot \operatorname{Ln}\left(\dot{\varepsilon}^{*}\right)\right]\left[1-\mathrm{T}^{*} \mathrm{~m}\right]
$$

where $\varepsilon$ is the equivalent plastic strain, $\dot{\varepsilon}^{*}$ is the dimensionless plastic strain rate (related to $\dot{\varepsilon}_{0}=1 \mathrm{~s}^{-1}$ ), and $\mathrm{T}^{*}=\left(\mathrm{T}-\mathrm{T}_{0}\right) /\left(\mathrm{T}_{\mathrm{m}}-\mathrm{T}_{0}\right)$ is the homologous temperature for $0 \leq \mathrm{T}^{*} . \leq 1$. The constants are $\mathrm{A}, \mathrm{B}, \mathrm{C}$, $\mathrm{n}$ and $\mathrm{m}$ (yield strength, work hardening coefficient, work hardening exponent, strain rate sensitivity and

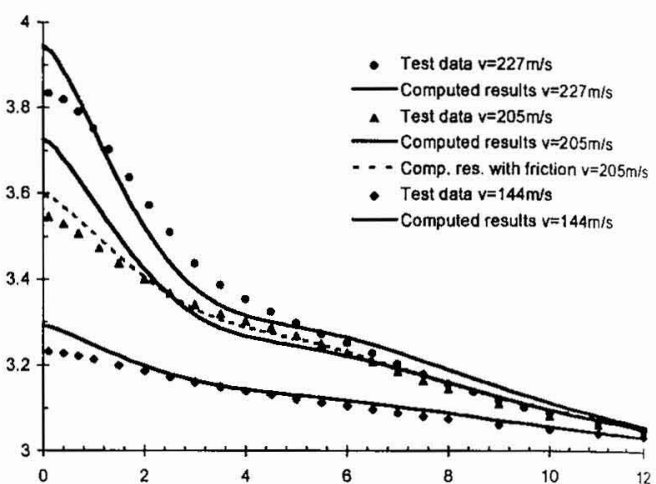

Figure 4: Comparison of computed/test results for steel I thermal softening coefficient). It is noteworthy that effects are uncoupled.

For the nitrogen alloyed steel $\mathrm{I}$, following equations can be fitted to the data tests: In isothermal conditions: $\sigma=\left[790+1300 . \varepsilon^{0.12}\right] \mathrm{MPa}$ for $\dot{\varepsilon}=0.001 \mathrm{~s}^{-1}$ $\sigma=\left[1110+1010 . \varepsilon^{0.12}\right] \mathrm{MPa}$ In adiabatic conditions: $\sigma=2400 \mathrm{MPa}$ for $\dot{\varepsilon}=1 \mathrm{~s}^{-1}$ (Curve $A$ in figure 1) for $\quad \dot{\varepsilon}=4100 \mathrm{~s}^{-1} \quad$ (Curve $\mathrm{C}$ in figure 1)

For the nitrogen alloyed steel II, a strain softening occurs $(\S 3.2)$, resulting from some damage that we tried to take into account. The Johnson-Cook model was modified; introducing some damage factor it was possible to fit the stress-strain curve with good accuracy. Thermal softening due to the increase of temperature by adiabatic conditions could also considered with a similar factor. However an equation without strain hardening was also proposed. Following equations were fitted to the results:

In isothermal conditions:

\begin{tabular}{|c|c|c|c|}
\hline$\sigma=\left[2050+80 . \varepsilon^{0.02}\right] \mathrm{MPa}$ & for & $\dot{\varepsilon}=0.001 \mathrm{~s}^{-1}$ & (Curve $\mathrm{A}$ in figure 2 ) \\
\hline$\sigma=\left[2275+80 . \varepsilon^{0.02}\right] /\left[1+0.18 \varepsilon^{0.4}\right] \mathrm{MPa}$ & for & $\dot{\varepsilon}=1 \mathrm{~s}^{-1}$ & (Curve $\mathrm{B}$ in figure 3 ) \\
\hline$\sigma=2260 \mathrm{MPa}$ & for & $\dot{\varepsilon}=1 \mathrm{~s}^{-1}$ & $\mathrm{e}$ in figure 3 ) \\
\hline $\begin{array}{l}\sigma=\left[2230+80 \varepsilon^{0.02}\right] /[1+0.88 \varepsilon] \mathrm{MPa} \\
\sigma=\left[2575+80 \varepsilon^{0.02}\right] /[1+0.88 \varepsilon] \mathrm{MPa}\end{array}$ & for & $\begin{array}{l}\dot{\varepsilon}=1 \mathrm{~s}^{-1} \\
\dot{\varepsilon}=2300 \mathrm{~s}^{-1}\end{array}$ & $\begin{array}{l}\text { (Curve } \mathrm{D} \text { in figure } 2 \text { and } 3 \text { ) } \\
\text { (Curve } \mathrm{E} \text { in figure } 2 \text { ) }\end{array}$ \\
\hline
\end{tabular}

\subsection{Comparison between computed and experimental results}

Cylinder-impact experiments provide an independent tool to evaluate the models, because they experience relatively high strains, high strain rates, and elevated temperatures. A two-dimensional axi-symmetric impact geometry is modeled using square $0.25 \times 0.25$ $\mathrm{mm}^{2}$ elements, i.e. 12 elements are used across the radius of the cylinder and 160 along the axis. Numerical simulations are carried out using the Johnson-Cook law implemented into LS-DYNA2D [7]. Specific values of the constants are given in Table 3. The thermal softening constant $\mathrm{m}$ is taken from literature [5]. II* denotes the second set of parameters used for steel II with the modification of the original law (curve B).

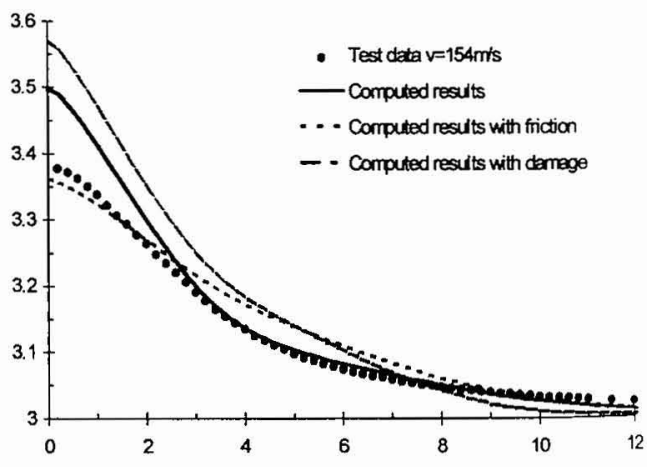

Figure 5: Comparison of computed/test results for steel II

The impact surface is firstly modeled as a rigid boundary, using a stonewall contact-impact algorithm (type 7) without friction, which allows the impacted end of the cylinder to mushroom and eventually the whole cylinder to rebound.

One aspect of the results is similar to a previous study [8], i.e. all the computations overestimate 
the maximum deformed radius of the specimens. That's why friction between the impacting cylinder and the near rigid tungsten carbide target is introduced in a second series of calculations. The interface is treated with a penalty formulation with friction (type 4), based on a Coulomb formulation.

To quantify the degree of agreement

Table 3 : Constants for the Johnson-Cook model

\begin{tabular}{|c|ccccc|}
\hline Steel & $\begin{array}{c}\mathrm{A} \\
(\mathrm{MPa})\end{array}$ & $\begin{array}{c}\mathrm{B} \\
(\mathrm{MPa})\end{array}$ & $\mathrm{n}$ & $\mathrm{C}$ & $\mathrm{m}$ \\
\hline $\mathrm{I}$ & 1110 & 1010 & 0.12 & 0.039 & 0.95 \\
\hline II & 2260 & $/$ & $/$ & 0.022 & 0.95 \\
\hline II* & 2275 & 80 & 0.02 & 0.019 & 0.95 \\
\hline
\end{tabular}
between computed shapes and test shapes, only post-tested configuration is considered and an average error is commonly defined as :

$$
\Delta=1 / 3[|\Delta \mathrm{L}| / \mathrm{L}+|\Delta \mathrm{D}| / \mathrm{D}+|\Delta \mathrm{W}| / \mathrm{W}] \quad \text { where } \mathrm{L}, \mathrm{D}, \mathrm{W} \text { are: }
$$

the deformed length, diameter and bulge diameter (at $0.2 \mathrm{~L}_{0}$ from the deformed end), measured from the test specimens, and $\Delta \mathrm{L}, \Delta \mathrm{D}, \Delta \mathrm{W}$ are the differences between the computed and test results [2].

Main results are reported in Tables 4 and 5. Run 1 is related to the simulations carried out with a stonewall option, Table 4 : Cylinder-impact test - Steel I

\begin{tabular}{|c|ccc|ccc|ccc|}
\cline { 2 - 10 } \multicolumn{1}{c|}{} & \multicolumn{3}{c|}{$\mathrm{v}=144.4 \mathrm{~m} / \mathrm{s}$} & \multicolumn{3}{c|}{$\mathrm{v}=204.5 \mathrm{~m} / \mathrm{s}$} & \multicolumn{3}{c|}{$\mathrm{v}=227 \mathrm{~m} / \mathrm{s}$} \\
\cline { 2 - 10 } \multicolumn{1}{c|}{} & test & run 1 & run 2 & test & run 1 & run 2 & test & run 1 & run 2 \\
\hline $\mathrm{L}(\mathrm{mm})$ & 38.89 & 38.83 & 38.87 & 37.70 & 37.67 & 37.78 & 37.07 & 37.11 & 37.24 \\
\hline $\mathrm{D}(\mathrm{mm})$ & 6.46 & 6.58 & 6.47 & 7.10 & 7.44 & 7.19 & 7.67 & 7.88 & 7.56 \\
\hline $\mathrm{W}(\mathrm{mm})$ & 6.15 & 6.18 & 6.19 & 6.29 & 6.32 & 6.31 & 6.32 & 6.38 & 6.37 \\
\hline$\Delta(\%)$ & & 0.83 & 0.29 & & 1.78 & 0.60 & & 1.26 & 0.89 \\
\hline
\end{tabular}
the calculations with friction are mentioned as run 2 (results are given for a frictional constant of 0.03 ) and run 3 deals with the modified Johnson-Cook model.

The model predictions and the test data are in close agreement. Introducing of friction at the interface between the cylinder and the near rigid target generally improves the results (see figure 4). Nevertheless, the average error is not a systematically reliable indicator. Looking at figure 5, it's not clear that an error divided by a factor of 4 means a better fit of the whole profile. One have to keep in mind that when using cylinder-impact experiments to determine constitutive model performance, the comparisons are only valid for the strains and strain rates experienced in these experiments, here for strains up to about 0.7 and strain rates in the region of $10^{5} \mathrm{~s}^{-1}$.

The tentative of including some damage into the

Table 5 : Cylinder-impact test - Steel II original constitutive law is inconclusive. This may be due to an erroneous assumption on the transposition of damage that occurs during the laboratory compression tests to the cylinder-impact configuration.

\section{Microscopic observations}

Figure 6 shows the micrograph of a quasistatically compressed specimen of steel I. Low deformed regions and a small high deformed band can be recognized. It is well known that macroscopic shear bands occur when the formation of twins is exhausted [5]. This will happen if grains are so strong deformed like steel I and II. Then deformation is mainly supported by a deformation band. That means that deformation cannot operate within grains any more. Shearing off of specimen regions occurs Macroscopic shearbands limit strain hardening (see $\$ 3.2$ ).

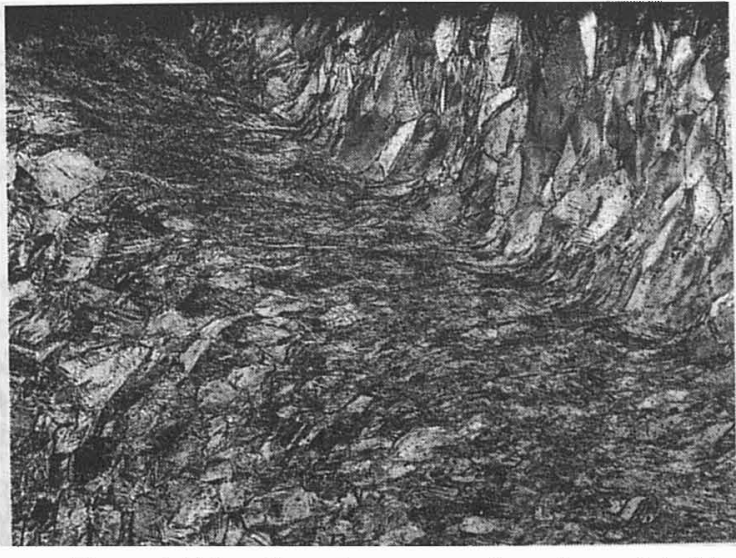

Figure 6: Edge of a static compressed specimen of steel I

Figure 7 shows a micrograph of a dynamically compressed specimen (steel I). A large amount of fine adiabatic shear bands can be seen. The width of these adiabatic shear bands is in the average $5 \mu \mathrm{m}$ and 
the microhardness amounts to HV0.1 $=800$.

Deformation in dynamic compression tests is only supported by adiabatic shear bands. It is supposed that adiabatic shear bands occur after some percent of strain and lead to a catastrophic failure

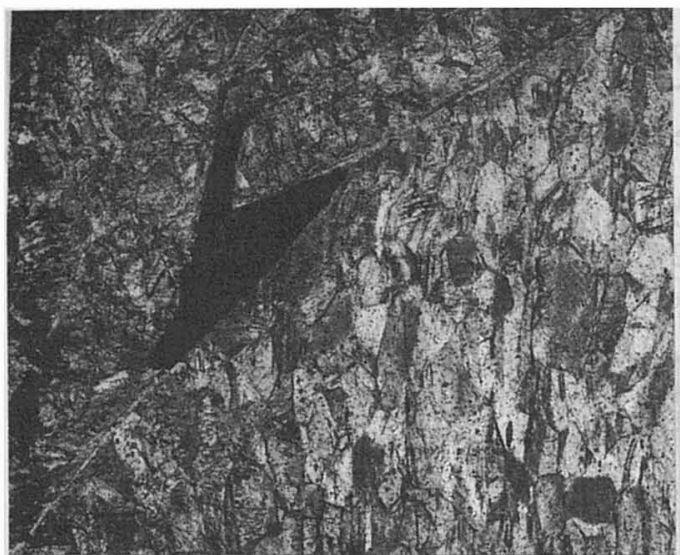

Figure 7: Adiabatic shear bands and damage in a dynamic compressed specimen of steel II

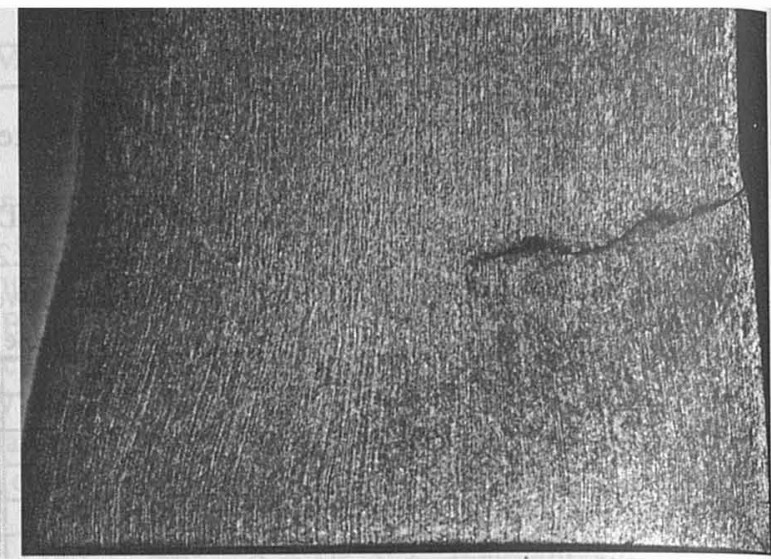

Figure 8: Damage in a Taylor test specimen of steel I

(see figure 3, 4 and 5). Due to the higher predeformation of steel II, failure occurs at lower strains.

A micrograph of a post-tested steel I specimen, after a Taylor test, is illustrated figure 8 in a longitudinal section. There is a macroscopic crack in the microstructure which can also be observed on the surface of the mushroomed part with an angle of $45^{\circ}$ towards the longitudinal axis. Underneath of this crack is an adiabatic shear band in an early state. It supports the assumption that formation of adiabatic shear bands occurs already at lower strain. The velocity of this specimen was only $1.3 \mathrm{~m} / \mathrm{s}$ higher than a specimen without macroscopic failure.

\section{CONCLUSION}

Dynamical behaviour of high strength nitrogen alloyed steels has been investigated. Those austenitic steels exhibit a high strain rate sensitivity, uncommon with FCC structures, showing a relatively high deformation before rupture.

Compression tests have been performed to determine most of the constants for the Johnson-Cook model and a close agreement was obtained comparing cylinder-impact test results with computed predictions, moreover when some friction is introduced in the simulation.

Microscopic observations after every dynamic compression test have revealed the formation of adiabatic shear bands at lower strain and the strain localization.

\section{References}

[1] Lach E., Uggowitzer P. J., Rondot F., Eurodymat 97, Toledo, 22-26 Sept. 1997,

[2] Holmquist T.J., Johnson G.R., Journal de physique IV, C3-853, Dymat 1991 (Strasbourg).

[3] Stein G., Menzel J.,. Choudhury A, Special Melting and Processing Technologies, San Diego, Apr., 1988, Noyes Publ., 1989, p. 579.

[4] Müllner P., Solenthaler C., Uggowitzer P. J., Speidel M. O., Acta metall. mater., 42 (1994) 2211-2217

[5] Paulus N.," Entwicklung von stickstofflegierten austenitischen Stählen höchster Festigkeit", Diss. ETH Nr. 10899, Zürich, 1994.

[6] Johnson G.R., Cook W.H., Proc. 7th Int. Symposium on Ballistics, The Hague, April 1983.

[7] Haliquist J.O., "User's Manual for I.S-DYNA2D, LSTC Report 1004, 1992. Revision 1993.

[8] Barton D.C.. Mirza M.S.. 7th Techni. Conf. DYMAT, 7-8 Oct. 1992 (ISL Saint-Louis). 